\title{
Awareness and perception of vasectomy among antenatal women in a tertiary health facility in southeast Nigeria
}

\author{
Lawrence C. Ikeako ${ }^{1 *}$, Johnpaul E. Nnagbo², Uchenna A. Umeh ${ }^{2}$, Hyginus U. Ezegwui², \\ Chibuike O. Chigbu², Leonard Ajah ${ }^{2}$, E. N. Onwudiwe ${ }^{2}$, Tochukwu C. Okeke ${ }^{2}$
}

\begin{abstract}
${ }^{1}$ Department of Obstetrics and Gynecology, Chukwuemeka Odumegwu Ojukwu University Teaching hospital, Amaku, Awka, Nigeria

${ }^{2}$ Department of Obstetrics and Gynaecology,University of Nigeria Teaching Hospital, Ituku-Ozalla, Enugu, Nigeria
\end{abstract}

Received: 27 February 2018

Accepted: 28 March 2018

\section{*Correspondence:}

Dr. Lawrence C. Ikeako,

E-mail: ikeakolawrence@yahoo.com

Copyright: () the author(s), publisher and licensee Medip Academy. This is an open-access article distributed under the terms of the Creative Commons Attribution Non-Commercial License, which permits unrestricted non-commercial use, distribution, and reproduction in any medium, provided the original work is properly cited.

\begin{abstract}
Background: Vasectomy is a safe alternative to bilateral tubal ligation (BTL) in achieving permanent sterilization but not popular in developing countries. As part of the efforts to increase popularity as well as acceptance of vasectomy in the developing countries, its awareness among women needs to be assessed. The study was undertaken to determine the awareness and perceptions of vasectomy among antenatal attendees in a tertiary health institution southeast Nigeria.

Methods: This was a questionnaire-based cross-sectional study in which pregnant women visiting University of Nigeria Teaching Hospital, Enugu (UNTH) antenatal clinic from 1st June - 30th November 2017 were recruited. Data was collected using structured questionnaire. Two hundred (200) self-administered questionnaires were completely filled and analyzed by means of descriptive and inferential statistics including means frequencies and $\mathrm{x}^{\wedge} 2$-tests at the $95 \%$ confidence level (CL).

Results: Of the 200 respondents, 146(73\%) were completely unaware of the existence of vasectomy while 54(27\%) were aware. Of those who were aware, 41(75.9\%) accepted its use as a family planning method for men. The commonest reason for acceptance was the fear of infidelity among their husbands, 17(41.5\%). The intention to use was however low as $24(44.4 \%)$ of those who accepted vasectomy disapproved of its use by their husbands and the main reason for disapproval was "weakens husband's sexual performance," (33.3\%). Tertiary level of education of the respondents was 5.3 times independently associated with the acceptance of vasectomy.

Conclusions: The awareness is low and there are several misperceptions about vasectomy among the women in Enugu. Tertiary education of the women however improves the choice of vasectomy as a permanent contraceptive option. There is the need for educational programmes in line with the numerous advantages of vasectomy so as to counteract the misperceptions especially those regarding sexual relationship.
\end{abstract}

Keywords: Awareness, Counselling, Misperceptions, Pregnant, Vasectomy, Women

\section{INTRODUCTION}

Maternal deaths from unexpected or unplanned pregnancies pose a major public health problem for women of reproductive age, particularly in developing countries. $^{1}$ Nigeria has one of the highest maternal mortality ratios in sub-Saharan Africa and ranks second as the country with the highest number of maternal deaths in the world, with illegal and unsafe abortions contributing $20-40 \%$ of about 60,000 maternal deaths that occur yearly. ${ }^{2,3}$ These preventable deaths are attributable 
to either lack of or inaccessible means of family planning in the communities. ${ }^{3}$

With an estimated population of 167 million accounting for over two-thirds of the population of West Africa, a growth rate of $28 \%$ and fertility rate of 6.5 births per woman, the overall contraceptive prevalence among women in Nigeria had only recently attained a double digit figure at $16 \% .{ }^{4}$ In the United Kingdom, the contraceptive prevalence among women ages 15-49 was reported at $84 \%$ and the maternal mortality ratio (MMR) was only 7 per 100,000 live births. ${ }^{5}$

The two methods of sterilization commonly employed when permanent contraception is needed include bilateral tubal ligation (female sterilization) and vasectomy (male sterilization). Bilateral tubal ligation (BTL) involves cutting the fallopian tubes via laparotomy, minilaparotomy or by laparoscopy. Vasectomy is the division or occlusion of the vas deferens which prevents passage of spermatozoa.

Several studies have shown that male sterilization (vasectomy) is effective, quick and simple to perform, offers permanent protection, convenient, no long term effect on his own health or sexual performance and no health risk for his wife. ${ }^{6,7}$ In spite of all these attributes, vasectomy still remains unpopular worldwide and developing countries in particular, compared to tubal sterilization $(3 \%-6 \%$ versus $28 \%){ }^{8}$

Male sterilization or vasectomy is a rarity among Nigerian men. ${ }^{9}$ There were only two cases of voluntary vasectomy performed over a 30 -year period at University College Hospital, Ibadan. ${ }^{9}$ In a study in Jos, Northern Nigeria, only 10 cases of vasectomy were recorded over a 16 year period compared with 3,675 female sterilizations. ${ }^{10}$ Studies have however shown that though demand for tubal ligation is also low in Nigeria, it is commonly accepted in conjunction with another surgical procedure such as caesarean section or laparotomy for repair of ruptured uterus. ${ }^{11}$

In India, the prevalence of female sterilization exceeds that of vasectomy by a factor of 37 to 1 with a current rate of $4.4 \% .{ }^{12}$ The rate of sterilization has fallen in England in a decade by three-quarters for women and by over half for men undergoing vasectomies as a result of increase in the number of couples using the Long Acting Reversible Contraceptives (LARCS). ${ }^{13}$ Low level of acceptance of vasectomy have also been attributed to lack of knowledge, wrong belief, myths and misconception regarding the procedure, lack of access, provider bias, patients' preferences and domineering influence of men in decision making process. ${ }^{6,7,14}$

It is possible that if women are better informed of the relative advantages of vasectomy, its acceptance as a permanent method of contraception may improve. However, to the best of our knowledge no study has been conducted in our environment on the awareness of vasectomy among antenatal women. This study was designed to determine the level of awareness and perception of vasectomy among women attending antenatal clinics in UNTH, Enugu.

\section{METHODS}

\section{Study Area}

This was carried out among pregnant women attending antenatal clinics at the University of Nigeria Teaching Hospital (UNTH), Ituku-Ozalla, Enugu, south-east Nigeria over a six-month period (1st June 2017 to 30th November 2017).

UNTH, Enugu was established about five decades ago and serves as a referral centre for obstetrics and gynaecological cases. The Hospital provides antenatal care for pregnant mothers and an average of 20 new clients are registered every week.

Enugu, an old regional capital is situated in the densely populated Igbo heartland of South-east Nigeria. It has an estimated population of 464,514 inhabitants made up civil servants and the indigenous dwellers who are predominantly engaged in trading, animal pasturing and subsistence farming. ${ }^{4}$ They are mainly Christians.

\section{Ethical approval}

Approval for this study was obtained from the Ethical Committee of UNTH, Enugu. Women who agreed to participate in the study were either asked to sign or thumb print the consent form depending on the level of literacy. They were assured of the confidentiality of any information given and if consent was refused, the quality of care would not be affected.

\section{Inclusion criteria}

The study population comprised of all pregnant women registering for antenatal care for the first time and had at least two children.

\section{Exclusion criteria}

Single, separated and divorced women and those whose husbands had undergone vasectomy were excluded. The study also excluded clients who have bad obstetric history (those whose previous pregnancies ended in miscarriages, stilbirths or perinatal deaths on one or more occasions).

\section{Study design and determination of sample size}

This was a descriptive cross-sectional survey using quantitative approach. The sample was calculated using the formula for estimated population size less than 10,000. 15 With $Z \alpha=1.96$ at 0.05 level of significance, 
power of $80 \%$ and $13 \%$ prevalence of modern contraceptive use among married Nigerian women, the calculated minimum sample size was $174 .^{2}$ Assuming an attrition rate of 20\%, 209 questionnaires were used.

The questionnaires were developed after extensive review of literature on family planning methods with emphasis on vasectomy. The questions were tested on a cohort of pregnant women in a nearby facility for clarity and to establish the Cronbach's alpha for reliability, which showed as 0.83 for awareness. Minor typographical errors were corrected.

The questionnaire consisted of sections on general characteristics of the respondents and awareness and perceptions of vasectomy. Preferences of the women for either method of permanent contraception (vasectomy and BTL) were also explored.

\section{Data Collection}

The sampling was consecutive and based on the calculated minimum sample size of 209 Consecutive consenting newly registered antenatal attendees were given the questionnaires. Adequate privacy was provided for the women during the interview. For women who could neither read nor write, the questionnaires were administered by a trained female member of the research team.

\section{Data analysis}

The analysis was done using SSPS statistical software version 17.0 for windows (Chicago IL, USA). Descriptive statistical methods such as mean, standard deviation, frequency and percentages were used.

A test of association between the variables was analyzed using the Pearson's chi-square test (cross tabulation) while logistic regression was used to test the strength of the association. A p-value of $\leq 0.05$ was considered significant. The results were displayed in tables and simple percentages.

\section{RESULTS}

Of the 209 questionnaires administered 200(95.7\%) were completely filled and were analyzed. Nine (4.3\%) were discarded on account of incomplete entries.

The mean age of the respondents was $32 \pm 17$ years, range 17-42 years. Table 1 shows the socio-demographic characteristics of the respondents. One hundred and ninety-two (96\%) and 196 (98\%) were Christians and of the Ibo ethnic group respectively.

One hundred and sixty-four (84\%) had tertiary education and $145(72.5 \%)$ were domiciled in the urban area.
Table 1: Socio-demographic characteristics of the respondents, $\mathbf{n}=\mathbf{2 0 0}$.

\begin{tabular}{|ll|}
\hline Variable & No $(\%)$ \\
\hline Age & \\
\hline $20-29$ & $43(21.5)$ \\
\hline $30-39$ & $101(50.5)$ \\
\hline $40-49$ & $56(28.0)$ \\
\hline Level of education & $164(82.0)$ \\
\hline University & $20(10.0)$ \\
\hline Secondary & $10(5.0)$ \\
\hline Primary & $6(3.0)$ \\
\hline None & \\
\hline Employment status & $112(56.0)$ \\
\hline Civil Servant & $51(25.5)$ \\
\hline Teaching & $37(18.5)$ \\
\hline House Wife & \\
\hline Male Children & $101(50.5)$ \\
\hline None & $99(49.5)$ \\
\hline One or more & \\
\hline Husband's level of education & $142(71.0)$ \\
\hline University & $39(19.5)$ \\
\hline Secondary & $11(5.5)$ \\
\hline Primary & $8(4.0)$ \\
\hline None & $145(72.5)$ \\
\hline Place of residence & $55(27.5)$ \\
\hline Urban & \\
\hline Rural & \\
\hline
\end{tabular}

One hundred and forty-six $(73 \%)$ respondents were unaware of vasectomy. Of the $54(27 \%)$ who were aware of vasectomy, $27(50 \%)$ were health workers. Sources of awareness were health workers $27(50 \%)$, mass media 10 $(18.5 \%)$, internet $9(16.7 \%)$ and friends and relatives 8 $(14.8 \%)$.

The perception of vasectomy was assessed by asking "whether they would suggest this method of operation for men as family planning method" and reasons for acceptance. Of the 54 who were aware, 41(75.9\%) accepted.

Table 2: Reasons for acceptance of vasectomy ( $N=41)$.

\begin{tabular}{|ll|}
\hline Reason for acceptance of vasectomy & No $(\%)$ \\
\hline Fear of infidelity & $17(41.5)$ \\
\hline Cheap and simple & $11(26.8)$ \\
\hline Participation of men in family planning & $10(24.4)$ \\
\hline Less side effects & $3(7.3)$ \\
\hline
\end{tabular}

The reasons given for acceptance are shown in Table 2 . The commonest reason was fear of infidelity (so that their spouses will not impregnate other women to avoid polygamy) $(41.5 \%){ }^{17}$

When specifically asked "if they would recommend vasectomy for their husbands", 24 (44.4\%) of the women who were aware disagreed. 
The reasons for disapproval are shown in Table 3. Eight (33.3\%) of those who disagreed said the operation may “weaken their husbands' sexual performance".

Table 4 shows the socio-demographic factors influencing the acceptance of vasectomy among women who were aware of vasectomy.

Level of education of the respondents, $\mathrm{p}=0.047$ and number of male children, $\mathrm{p}=0.016$ were significantly associated with the acceptance of vasectomy. In multivariate analysis, only level of education [OR 5.3; 95\% CL (1.2-22.15)] was independently associated with the acceptance of vasectomy.
Table 3: Reasons for disapproval of vasectomy $(\mathrm{N}=\mathbf{2 4})$.

\begin{tabular}{|ll|}
\hline Reason for disapproval & No $(\%)$ \\
\hline Weakens husband's sexual performance & $8(33.3)$ \\
\hline Desire for more male children & $6(25.0)$ \\
\hline Against religious belief & $5(20.8)$ \\
\hline Result in infertility in next life & $5(20.8)$ \\
\hline
\end{tabular}

When asked to choose between the two methods of sterilization (permanent contraception), more than half of all the respondents, $116(58 \%)$ preferred vasectomy to BTL, $84(42 \%)$.

Table 4: Socio-demographic factors influencing awareness/acceptance of vasectomy.

\begin{tabular}{|c|c|c|c|c|}
\hline Variable & Acceptance & Non-acceptance & Total & P Value \\
\hline & $\mathrm{N}=41$ & $\mathrm{~N}=13$ & $\mathrm{~N}=54$ & \\
\hline & $\mathrm{N}(\%)$ & $\mathrm{N}(\%)$ & $\mathrm{N}(\%)$ & \\
\hline \multicolumn{5}{|l|}{ Age(years) } \\
\hline$<30$ & $19(46.3)$ & $6(46.2)$ & $25(46.3)$ & \\
\hline$\geq 30$ & $22(53.7)$ & $7(53.8)$ & $29(53.7)$ & 0.221 \\
\hline \multicolumn{5}{|c|}{ Level of education } \\
\hline Tertiary & $35(85.4)$ & $4(30.8)$ & $39(72.2)$ & \\
\hline Non-Tertiary & $6(14.6)$ & $9(69.2)$ & $15(27.8)$ & 0.047 \\
\hline \multicolumn{5}{|c|}{ Employment status } \\
\hline Employed & $20(48.8)$ & $7(53.8)$ & $27(50.0)$ & \\
\hline Not Employed & $21(51.2)$ & $6(46.2)$ & $27(50.0)$ & 0.124 \\
\hline \multicolumn{5}{|c|}{ No of male children } \\
\hline None & $4(9.8)$ & $9(69.2)$ & $13(24.1)$ & \\
\hline One or more & $37(90.2)$ & $4(30.8)$ & $41(75.9)$ & 0.016 \\
\hline \multicolumn{5}{|c|}{ Husband's level of education } \\
\hline Tertiary & $32(78.0)$ & $10(76.9)$ & $42(77.8)$ & \\
\hline Non-Tertiary & $9(22.0)$ & $3(23.1)$ & $12(22.2)$ & 0.821 \\
\hline \multicolumn{5}{|c|}{ Place of residence } \\
\hline Urban & $29(70.7)$ & $8(61.5)$ & $37(68.5)$ & \\
\hline Rural & $12(29.3)$ & $5(38.5)$ & $17(31.5)$ & 0.065 \\
\hline \multicolumn{5}{|l|}{ Religion } \\
\hline Christian & $36(87.8)$ & $11(84.6)$ & $47(87.0)$ & \\
\hline Non-Christian & $5(12.2)$ & $2(15.4)$ & $7(13.0)$ & 0.712 \\
\hline \multicolumn{5}{|l|}{ Ethnic group } \\
\hline Ibos & $39(95.1)$ & $11(84.6)$ & $50(92.6)$ & \\
\hline Non-Ibos & $2(4.9)$ & $2(15.4)$ & $4(7.4)$ & 0.802 \\
\hline
\end{tabular}

\section{DISCUSSION}

The level of awareness of vasectomy among the antenatal attendees in this study, 27\% was low when compared with reports from Nepal, $77 \%$ and Port Harcourt, $55.3 \% .^{14,16}$ Alemayehu et al reported a lower level of awareness, $15.6 \%$ among married women of reproductive age in Tigray region, north Ethiopia. ${ }^{17}$ In a comparative study of married men and women in Lagos, Nigeria Tijani et al observed that the level of awareness and knowledge of vasectomy was poor in both sexes but was better in men than women $(27.5 \%$ versus $21 \%) .{ }^{18}$

The low level of awareness in this study could have profound impact on acceptance since the influence on the partners' choice of contraception may not to be limited to the male alone as the female could have strong influence on the male partners. ${ }^{14}$ Tijani et al observed that $93 \%$ of all women believed their husbands would seek their approval before going ahead with any form of permanent 
contraception and $92.3 \%$ of all men who are willing to accept vasectomy can only do so if their wives were in support. ${ }^{18}$

The sources of information in this study were mainly from health workers. The observation that $50 \%$ of those who knew about vasectomy were either health workers or related to health workers could have a salutary effect in conveying evidence-based information to their spouses. In a descriptive study of 140 men in Edo state, Nigeria Onasoga et al observed that poor knowledge of vasectomy was evident owing to the fact that the sources of information of the respondents were largely from friends and partners. It is however important that the information from health workers to the clients is given without prejudice. ${ }^{19}$

In their survey of attitudes, counselling patterns and acceptance of vasectomy among Nigerian Resident Gynaecologists, Ebeigbe et al advised against the involvement of health personnel biased against use of vasectomy as he or she may consciously or unconsciously transfer the biases to the patients. ${ }^{20}$

About $75.9 \%$ of the women who were aware in this study were in support of vasectomy for family planning. The high rate of acceptance in our study may be due to the perceived benefits; check against infidelity, participation of men in regulating family size, safety and lower costs compared to tubal ligation. In a cross-sectional study among 150 antenatal clinic attendees in Port Harcourt, Nigeria, $71 \%$ of the women accepted vasectomy due to less side effects and effectiveness. ${ }^{16}$

This was also evident in a study in Cambodia where women alluded to the benefits of sharing family planning responsibilities while in Tanzanian women welcomed the possibility of eliminating having a child out of wedlock through vasectomy. ${ }^{21,22}$

Perception of vasectomy may play a crucial role in the willingness of women to convince their spouses to undergo such a procedure. ${ }^{12}$ This study showed the respondents objected to vasectomy because of the perception that it will affect sexual performance of their husbands, $33.3 \%$ and could also result in infertility in the next life, $20.8 \%$. In other studies, participants perceived that vasectomy will devalue a man's economic contributions and the man could be viewed as "under the control" or a "slave to" his wife. ${ }^{23}$ Inaccurate knowledge often fuels erroneous assumptions and misperceptions about how vasectomy affects men physiologically and psychologically. ${ }^{8}$ This underscores the need for mass education and sustained advocacy to address so many entrenched misconceptions and rumors on the procedure. ${ }^{8}$

Our study revealed a low intention to use vasectomy. It was observed that though $75.9 \%$ of respondents who were aware approved of vasectomy, only $41.5 \%$ were willing to recommend the procedure for their husbands.
In Port Harcourt, Nigeria, 39\% of the antenatal clinic attendees would allow their husbands have a vasectomy whereas $61.0 \%$ disapproved of it. ${ }^{16}$ In a descriptive crosssectional study on 200 married men in Kathmandu, Nepal, the intention to accept vasectomy among married men was low and the wife's disapproval came out as the major factor influencing men's intention not to accept vasectomy. ${ }^{14}$

The low rate of approval in this study may be attributed to the low level of awareness and misconceptions among the women. A couple counseling system to address the knowledge gaps and several negative misperceptions may help the women motivate their husbands to accept the procedure. $^{14}$

The number of male children and educational level of the women were determinants of the likelihood of acceptance of vasectomy in this study. In our traditional marriage system, having a male child is viewed as important so as to attain prime position on the issue of inheritance of properties on the death of the family head. ${ }^{24}$ Similarly, Mahat et al assessed the role of the son in Hinduism as critical in religious rituals and death anniversaries of parents in Kathmandu, Nepal. ${ }^{14}$ In addition, having more than one son is considered a safeguard in view of Nigeria's high infant mortality rate at 69.49 deaths per thousand live births. ${ }^{4}$

In support of our findings, level of education in a multistage study of barriers and facilitators affecting vasectomy acceptability in Iran was significantly higher among couples who accepted vasectomy. ${ }^{7}$ This may be explained by an increased health awareness, better understanding of family planning methods and also the likelihood of positively adopting advice from health workers. ${ }^{25}$ More than half of the respondents in this study, $58 \%$ preferred vasectomy to BTL. This may be an attempt to elicit greater involvement of males in family planning. This is in line with other reports. ${ }^{69}$

The study has some limitations. We considered only females for this research. The opinion and knowledge of males should be considered in future research as this may help in better family planning. This study was also carried out in an area predominantly inhabited by Christians and Ibo ethnic group. A wide spectrum, multicentric study in the future including other religions and ethnic groups in Nigeria may provide a clear scenario.

\section{CONCLUSION}

Though there is preference for vasectomy over BTL by antenatal women, awareness is still low. High educational level however improves the choice of vasectomy as a permanent contraceptive option. There is need for educational programmes in line with the numerous advantages of vasectomy so as to counteract the misperceptions especially those regarding sexual problems. 
Funding: No funding sources

Conflict of interest: None declared

Ethical approval: The study was approved by the Institutional Ethics Committee

\section{REFERENCES}

1. Tsui AO. Family planning and the burden of unintentional pregnancies. Epidemiol Rev. 2010; 32(1):152-74.

2. Monjok E, Smesny A, Ekabua JE, Essien E. Contraceptive practices in Nigeria: Literature review and recommendation for future policy decisions. $\mathbf{J}$ Contracep. 2010;1:9-22.

3. Bankole A, Adewole IF, Hussein R, Awolude O, Singh S, Akinyemi JO. The incidence of abortion in Nigeria. Int Perspect Sex Reprod Health. 2015; 41(4):170-81.

4. National Population Commission (NPC) [Nigeria\} and ICF International. Nigeria Demographic and Health Survey 2013. Abuja, Nigeria, Rockville, Maryland, USA: NPC and ICF International.

5. United Kingdom - Contraceptive prevalence $\%$ of women ages.2009:15-49.

6. Shih G, Zhang Y, Bukowski K, Chen A. Bringing men to the table: sterilization can be for him or for her. Clin Obstet Gynecol. 2014;57(4):731-40.

7. Keromat A, Zarei A, Arabi M. Barriers and facilitators affecting vasectomy acceptability (a multi stages study in a sample from north eastern Iran), 2005-2007. Asia Pac Fam Med. 2011;10(1):5-11.

8. Shattuck D, Perry B, Packer C, Quee DC. A review of 10 years of vasectomy programming and research in low-resource settings. Glob Health Sci Pract 2016; 4(4):647-60.

9. Akinwutan AL, Shittu OB. Voluntary vasectomy in a Nigerian: A rarity. Afri J Med Sci. 2008;37:289-90.

10. Mutihir JT, Ugah IAO, Ekwempu CC, Duru PH, Aisien OA. Acceptability of vasectomy in Jos, northern Nigeria. Trop J Obstet Gynaecol. 2004; 2(1):56-7.

11. Ezegwui HU, Nwogu-Ikojo EE. Sterilization at Caesarean Section in Nigeria. Int J Gynaecol Obstet. 2004; 87(2):157-58.

12. Saoji A, Gumashta R, Hajare S, Nayse J. Denial mode for vasectomy in Central India: Causes and Suggested Strategies. J Psychol Psychother. 2013; 3(4):120-5.

13. Connolly A, Pietri G, Yu J, Humphreys S. Association between long-acting reversible contraceptive use, teenage pregnancy and abortion rates in England. Int J Women's health 2014;6:96174.

14. Mahat K, Pacheun O, Taechaboonsermask P. Intention to accept vasectomy among married men in
Kathmandu, Nepal. Asia J Public Health. 2010; 1(1):8-14.

15. Margaret AD. Research methodology with statistics for health and social sciences. $1^{\text {st }}$ ed. Ilorin, Nigeria. Nathader Publisher. 2003;115-21.

16. Nyengidiki KT, Orji V, Olaka EW. Knowledge and attitude toward vasectomy among antenatal clinic attendees in a tertiary health facility in Nigeria. Sahel Med J. 2016;19(4):201-5.

17. Alemayehu M, Belachew T, Tilahum T. Factors associated with utilization of long acting and permanent contraceptive methods among married women of reproductive age in Mekelle town, Tigray region, north Ethiopia. BMC Pregnancy Childbirth 2012;12(1):6-16.

18. Tijani KH, Ojewola RW, Yahya GL, Oluwole AA, Odusanya B. Attitudes and acceptance of Nigerians towards vasectomy - A comparison of married men and women in Lagos. East Afri Med J. 2013:90(3):89-94.

19. Onasoga OA, Edoni EE, Ekanem J. Knowledge and attitudes of men towards vasectomy as a family planning method in Edo State, Nigeria. J Res Nursing Midwifery 2013;2(1):13-21.

20. Ebeigbe PN, Igberase GO, Eigbefoh J. Vasectomy: A survey of attitudes, counselling patterns and acceptance among Nigerian Resident Gynaecologists. Ghana Med J. 2011;45(3):101-4.

21. Yinger N, Ramage I, Holden J, Nicewinter JP, Ramage KH. View on family planning and long acting methods: insights from Cambodia. New York: EngenderHealth, RESPOND Project; 2013. Project Brief No. 12.

22. Bunce A, Guest G, Searing H, Frajzyngier V, Riwa $\mathrm{P}$, Kanama J, Achwal I. Factors affecting vasectomy acceptability in Tanzania. Int Fam Plan Perspect. 2007;33(1):13-21.

23. Hall MA, Stephenson RB, Juvekar S. Social and logistical barriers to the use of reversible contraception among women in a rural Indian village. J Health Popul Nutr. 2008;26(2):241-50.

24. Adebimpe WO, Asekun-Olarinmoye E, Bamidele JO Aboderin O. Continental J Med Res 2011;5(1):3240.

25. Dayanand G, Singh S, Baruwal C. An assessment of knowledge and attitude of vasectomy in adult males; a cross sectional study from Pokhara, Western Nepal. Med Sci. 2014;2(4):164-70.

Cite this article as: Ikeako LC, Nnagbo JE, Umeh UA, Ezegwui HU, Chigbu CO, Ajah L. et al. Awareness and perception of vasectomy among antenatal women in a tertiary health facility in southeast Nigeria. Int J Reprod Contracept Obstet Gynecol 2018;7:1706-11. 